\title{
Técnica e humanismo \\ na poesia de Michel Deguy ${ }^{1}$
}

\section{Marcos Siscar}

\section{A retração da natureza}

"A terra se retrai, se retira, vazante de natureza sob os nitratos" ". O alarme disparado pelo poeta denuncia as disposições do "tempo do mundo finito", de que fala Baudelaire, um mundo onde o humano se identifica consigo mesmo por oposição à natureza, ampliando o domínio do artifício até transformar-se ele próprio em um resultado da técnica, como que a sucedendo; isto é, de fato, até chegar a recusar essa técnica como componente ou contemporânea de sua humanidade. Esse pensamento eco ou geopoético ${ }^{2}$ na poesia de Michel Deguy se elabora em paralelo com suas proposições acerca do que antes tinha o nome de "progresso" (palavra que atravessa a tradição de Baudelaire a Bataille); ele marca a reflexão política sobre a monstruosidade do humanismo contemporâneo e a capacidade que o autor tem de despertar a singularidade dos objetos do mundo, procedimento que ele chama de "prosopopéia".

A natureza - ou ao menos os lugares situados às "orlas" da natureza - é um topos importante na poesia de Deguy, sobretudo nos primeiros poemas. A casa, o campo, a floresta, as crianças, "Daqui se vê o interior"*. Essa paisagem natural, embora repleta de pontos cegos, torna-se um elemento cada vez mais silencioso na obra do poeta, e é guardada nos limites da memória:

\footnotetext{
${ }^{1}$ Trabalho apresentado no colóquio internacional sobre Michel Deguy, em Cerisyla-Salle. A presente versão foi traduzida por Milena Magalhães, em colaboração com o autor. As traduções de poemas e textos de Deguy aproveitam as versões incluídas em Deguy, Michel. A rosa das línguas. Apresentação, tradução e notas de Paula Glenadel e Marcos Siscar. (São Paulo/Rio de Janeiro: Cosac \& Naify/Sette Letras, 2004).

${ }^{2}$ Segundo a palavra retomada por Derrida (“Comment nommer". Em: Charnet, Yves (org.) Le poète que je cherche à être (Cahier Michel Deguy) (Paris: La Table Ronde/ Belin, 1996). Ver também "Uma geopoética do 'como-um”, de Paula Glenadel (Em: Deguy, Michel. A rosa das línguas. Ob. cit.). Em O impar, Deguy faz a relação entre ecologia e poética planetária: "A ecologia não acredita de modo algum na Natureza. A Natureza teve lugar... O ecólogo, nem naturista nem nudista, tampouco é um empregado municipal ocupado com problemas de evacuação de dejetos ou de meio-ambiente. Ele é um geopoético” (: 265).
}

" “D'ici on voit à l'intérieur"
(Fragments du cadastre
(1960). Em: Deguy, Michel.
Poèmes (1960-1970). Pa.
ris: Gallimard, 1973: 12).

"La terre se rétracte, se retire, jusant de nature sous les nitrates" (Deguy, Michel. L'Énergie du désespoir. Paris: PUF, 1998: 23). 
" (Deguy, Michel. Le Spleen de Paris. Paris: Galilée, 2001: 21).

" (Pachet, Pierre. Vitesse dans la poésie et dans la vie. Em: Charnet, Yves (org.) Le poète que je cherche à être (Cahier Miche Deguy). Ob. cit: 1996.)

"(Deguy, Michel. Le spleen de Paris. Ob. cit: 15)

" (Cf. Thélot, Jérôme. Bau delaire: violence et poésie. Paris: Gallimard, 1993.)
A orla, o caminho no crepúsculo. Ao pensar nisso, eu choro o muito antigo, o muito pesado, a outra vida. Penso nisso como no crescimento, na crença. $\mathrm{O}$ amor serrado pelos seres, a vida próxima em seu minar, a intimidade, a continuidade.
La lisière, le chemin au crépuscule. Y pensant, je pleure le très ancien, le très lourd, l'autre vie. J'y pense comme à la croissance, à la croyance. L'amour étroit pour des êtres, la vie proche dans son sourdre, l'intimité, la continuité."

A natureza se retrai nos escritos de Deguy, ao mesmo tempo que se subtrai sob a domesticação tecnoeconômica. Atenta ao que sucede, ao que acontece, sua poesia torna-se obstinadamente urbana, e também atua na rapidez e na descontinuidade. Reconhecendo-se na "frequentação de cidades enormes" (Baudelaire), transformada em realidade intransponível de histórias individuais ínfimas e narráveis, sacrificadoras e sacrificadas*, o poeta reivindica então sua "grande paixão" da adolescência: Baudelaire. O flâneur de Deguy se mistura à multidão, mas a multidão, por vezes, somente se torna sensível ao alcance do avião, globalizada, convertida em mistura de indivíduos e hábitos percebidos a partir de seus lugares geográficos. Reconhecemos também os procedimentos do homem que flana ou, antes, do homem de modernidade ${ }^{3}$, quando este recusa a presunção de inocência, isto é, de neutralidade, e assume os riscos dessa rapidez, a escrita fragmentária, descontínua, o estilo da anotação, os atalhos das referências literárias e filosóficas. Deveríamos analisar essa rugosidade discursiva com os mesmos cuidados com que falamos, por exemplo, da "violência" baudelairiana*, mas sua particularidade tem um sentido mais próximo do interesse que a poesia de Deguy demonstra pela "singularidade" do acontecimento.

Se acontecimentos singulares não deixam de acontecer nas grandes cidades do mundo, o que evidentemente exclui a idéia de uma poesia turística, a travessia retoma, antes de tudo, a aventura grega do retorno, da eleição de um em casa paralelo à errância poética planetária: é perceptível, em Deguy, os movimentos em direção a uma figura do centro:

\footnotetext{
${ }^{3}$ Michel Foucault situa essa distinção em Baudelaire como um dos aspectos de seu processo de "heroificação irônica do presente": "Aquele que flana se contenta em abrir os olhos, prestar atenção e colecionar na lembrança”. Quanto ao homem da modernidade, "ele vai, corre, procura", segundo as palavras de Baudelaire. Cf. Foucault, Michel. Arqueologia das ciências e histórias dos sistemas de representação (Rio de Janeiro: Forense Universitária, 2000).
} 
[...] retomar tangência suavemente no solo de Roissy ou de Orly, fender a periferia pelas suas falésias envidraçadas […] desafivelar a cintura das vias marginais, arrancar a pele dos subúrbios, fazer contagem regressiva pelos distritos até o coração... Burguês de Paris? Sim.
[...] reprendre tangence en doucheur avec le plancher de Roissy ou d'Orly, fendre la banlieue par ses falaises vitreuses [...], déplier la ceinture périphérique, dépiauter les faubourgs, compter à rebours les arrondissements jusqu'au coeur... Bourgeois de Paris? Oui. ${ }^{*}$
"(Deguy, Michel. Le Spleen de Paris. Ob. cit.: 21).

O centro é aqui o elemento de uma espécie complexa, mas não complexada, de filiação (talvez) conquistada. Paris não é somente a cidade nacional com a qual se identifica o poeta; é também figura de uma singularidade possível. Se a referência às grandes cidades do mundo proporciona a demonstração dos efeitos da técnica em escala global, é ainda mais significativo que em Paris, como em nenhuma outra parte, diante da mesma lógica mundial, esteja em jogo para o poeta a possibilidade e a necessidade do poema. Está em jogo aí uma poética e uma ética, uma "po-ética” [poéthique] que, a meu ver, se afirma principalmente a partir das figuras da técnica.

\section{A marca da técnica}

A importância do problema da técnica como topos de escrita em Michel Deguy é notória. Retraindo-se desde suas primeiras obras, a interioridade natural se abre aos problemas da lógica economista em escala mundial - que pensa a cultura como sintoma ("Lutero e os bardos N’zakara/ Concordam quanto à cozinha”)* - e o pensamento poético torna-se mais atento às feridas infligidas ao planeta ("o abcesso profundo da Amazônia”)*.

"Esta terra é nossa, dizia o gerente das Malvinas. Os primeiros homens haviam chegado sem mulheres, e tinham que ir procurá-las nos portos"*. Como se fosse dada uma nova "largada”, um novo começo que não é somente um dado do "novo mundo" americano, mas de um mundo novo enquanto americano. Nesse mundo, a antiga habitação biológica é substituída pela idéia de propriedade possibilitada pelo poderio tecnomilitar; a terra recomeça contrariando a narrativa do começo, propondo uma gênese contranatural, uma gênese sem mulheres (com exceção daquelas encontradas, para o prazer, nos limites da terra: "portos”). A circulação se acelera nos textos de Deguy; o

"Luther et les bardes N'zakara/ Tombent d'ac. cord sur la cuisine" (Oui dire (1966). Em: Deguy, Michel. Poèmes (1960. 1970). Ob. cit.: 53).

" "l'abcès profond de l'Ama. zonie". Em: Deguy, Michel. Actes. Paris: Gallimard, 1966: 86)

" "Cette terre est à nous, disait le gérent des Malvinas. Les premiers hommes étaient arrivés sans femmes, et ils de vaient aller en chercher jusqu'aux ports" (: 95) 
" "notations voyageuses". (Deguy, Michel. Choses de la poésie et affaire culturelle. Paris: Hachette, 1986: 175).

" (Deguy, Michel. Jumelages. Paris: Seuil, 1978).

" (Deguy, Michel. Choses de la poésie et affaire culturelle. Ob. cit.: $82 \cdot 3$ ) gênero diário, o gênero da anotação (cadernetas) se põe então em marcha, a fim de poder acolher (ao ritmo das "anotações de viagem"*; a necessidade de um deslocamento acelerado através do planeta, única escala capaz de desenhar os contornos ou os circuitos de um novo começo, de um acordo novo e inquietante sobre a vida em comum.

O poder devastador da técnica pode agora ser medido por seus dispositivos químicos, seu poder de criar novas moléstias ou de multiplicar as já conhecidas; seu drama se reveste de figuras explosivas sob o fundo da Guerra Fria. Basta lembrar "A rosa das línguas de Paris", poema conhecido por sua importância na constituição da obra do poeta como bússola dos grandes tremores geopolíticos:
[...] grandes doenças, asbestose, febres porcinas, mal de Miramata, cloracne, pneumonias fulminantes e restos de plutônio a vigiar durante 500.000 anos

hexaclorofeno vagando desde o $48^{\circ}$ paralelo, agora estagnado sobre Milão (roedores sufocam, coze a derme de crianças, mulheres abortam)

hidras MIRV ICBM, backfire Poseidon em alerta ISQ, tridentes de 24 mísseis de $7.200 \mathrm{~km}$ de alcance "capazes de destruir qualquer nação do globo", USA 8.500 ogivas, URSS mais de 3.000, e em Vladivostock 21.000 ogivas "autorizadas",

Viking a 815 milhões de $\mathrm{km}$ persegue óxido de ferro no planeta vermelho
[...] grandes maladies, abestose, fièvres porcines, mal de Miramata, chloracné, pneumonies foudroyantes, et restes de plutonium à surveiller pour 500000 ans

hexachlorophène errant depuis le $48^{\mathrm{e}}$ parallèle, stagné maintenant sur Milan (rongeurs suffoqués, derme d'enfants bouilli, femmes avortées)

hydres MIRV ICBM, backfire Poseïdon en alerte ISQ, tridents à 24 missiles de $7.200 \mathrm{~km}$ de portée "capables de détruire n'importe quelle nation du globe", USA 8.500 ogives, URSS plus de 3.000, et à Vladivostock 21.000 ogives "autorisées",

Viking à 815 millions de km de l'oxyde de fer sur la planète rouge*
A tonalidade apocalíptica oscila entre a descrição de um estado de fato, isto é, dos discursos sobre os perigos presentes, e o julgamento desse estado como "contratempo" infligido pelo humano a si mesmo. A questão não é simples e é preciso considerar também suas transformações históricas. Da técnica ameaçadora, que a marcha da liberdade entendia (e ainda entende) como uma espécie de "mal necessário", passamos a 
uma situação na qual a violência se apresenta por meio do eufemismo do espetáculo, em que a técnica se apresenta como coisa desejável.

Se os efeitos apocalípticos não estão excluídos, manifestando-se em geral eufemisticamente, o estado de coisas contemporâneo nos aproxima sobretudo da sedução da técnica. Essas mudanças de cabo são perceptíveis, por exemplo, na análise que Deguy propõe sobre os significantes da publicidade da R.A.T.P., empresa de transporte coletivo, na França: "A meu ver, eu os carrego. Vocês me carregam junto"*. A sedução age pela idéia de "rapto" (contido anagramaticamente nas iniciais da empresa, e na própria semântica da palavra emporter, carregar energicamente, apaixonadamente), pelo conforto da velocidade, instaurando a cumplicidade entre a técnica como meio e a técnica como finalidade. $\mathrm{Na}$ absoluta aparência de eficácia e praticidade, há sempre um “eu” que exulta, simplesmente por tê-la produzido: "No vagão de primeira classe do TGV onde não há 'ninguém', 'eu' me lanço, chicoteio o trem de inferno panorâmico, que sobrevoa o mundo a $300 \mathrm{Km} /$ hora em absoluto conforto"*. Essa situação do rapto tecnológico, da "identidade entre meios e fins"*, cujo exemplo da apelação musical "tecno" é o mais evidente (spleen de Paris), poderia designar o estado extremo do modo de relação com a técnica no contemporâneo. A “ameaça” está também nas artes, quando estas se tornam “ébrias de tecnologia” e se contentam com um mimetismo fácil que capta “o real em 'alta fidelidade”* Não se trata mais da técnica entendida como luxo perigoso, e sim como fato divinizado da "supremacia humana"*4.

A aproximação com os fatos da cultura é possível de ser feita, e esse é um dos comparantes que mais interessa a Deguy. O cultural, segundo o autor, é uma generalização da iteração ou da indistinção no domínio da cultura, dos arquivos, dos

"A técnica é geral, não é mais um fato do "centro" do capitalismo. "[ ...] lá, em Ogaden, na Amazônia, na Indonésia, no Bangladesh ou em Serra Leoa, estão as multidões desprovidas do terceiro e do quarto mundo, os contaminados, os mais mortais, atrás da tela da televisão, imóveis...” (Deguy, Michel. Le spleen de Paris. Ob. cit.: 23). A técnica também está ali, restando decidir quem é "o mais mortal”. Após ter comentado a "desproporção" produzida pelo Ocidente economicista, a superioridade do homem sobre o homem, Deguy mostra o exemplo do "milionário folgado ultrapassando por sua vez, sobrevoando em seu jato particular o lento TGV onde [o poeta começou sua ] parábola" (: 23). A desproporção não coincide com o geográfico, mesmo que este seja exemplar e dramático; a própria técnica é figura dessa desproporção. A distância destrutiva da técnica está no desejo de superioridade do qual ela é o meio e o objeto.
" "Selon moi je vous em. porte. Vous m'emportez avec" (: 122).

\footnotetext{
"Dans le wagon de pre mière classe du TGV où il n'y a "personne", "je" fonce, je fouette le train d'enfer panoramique, qui survole le monde à 300 kilomètres/heure dans l'absolu confort" (Deguy, Michel. Le spleen de Paris. Ob. cit.: 22).

" "I'identité des moyens et
} des fins" (: 23)

\footnotetext{
" "le réel en "haute fidélité" (Deguy, Michel, La raison poétique. Paris: Galilée, 2000: 17).

"(Deguy, Michel. Le spleen de Paris. Ob. cit.: 22-3)
} 
patrimônios, dos valores turísticos. É também um modo de excluir as habitações e as tonalidades tradicionalmente nomeadas humanas, a favor de um espírito de conservação, cujo objetivo não é outro senão ele mesmo, produzindo o vazio no interior do sentido do mundo. Cito a última estrofe de "Europa em Lisboa":

Da Torre de Belém à Torre de Stephen De la Tour de Belem à la Tour de Stephen

Quero não censurar o sentido da visita Je veux ne pas médire du sens de la visite

Autorizada pelo ticket cultural poliglota Qu'autorise le ticket culturel polyglotte

Eu seguia no vão da escada a empregada J'y suivais dans la cage la femme de ménage

Que tem por função manter bem vazio este vazio Qui a la fonction de bien tenir ce vide bien à vide

Amarrar o laço da pedra no terceiro andar De nouer la faveur de la pierre au troisième palier

E arrumar turbantes, de pedra, escudos, de pedra, [de sultão, de cruzado

Et de ranger turbans, de pierre, écus, de pierre, [de sultan, de croisé

arrumar um retorno de ménager retour

para o amor que não voltará. à l'Amour qui ne reviendra pas*

Podemos perceber que o pensamento de Deguy se arrisca decididamente a penetrar na história e na particularidade de seus estados. A faxineira portuguesa é uma figura dessa história que circula, que se define historicamente, na medida em que esvazia o sentido do lugar (incluindo-se aí o do "sebastianismo", de um messianismo tradicional, ou seja, tornado anacrônico, fora de seu lugar, pois o Amor não voltará).

Entretanto o procedimento não é o mesmo da crítica cultural. Não há em Deguy nem uma nostalgia do natural, nem tampouco (o que é mais discutível) uma crença no estado do presente como sentido determinado; o presente não é visto como tempo em que a técnica completou-se, concluiu-se em seu sentido. Arriscar-se na história quer dizer aqui lançar-se à aventura da singularidade, sem perder de vista a contrariedade desse gesto. Se a técnica assumiu o nome de "América", 
não podemos esquecer que “América' desperta cada um para sua contradição"*. Ora, a técnica se define, mais fundamentalmente, como repetição, como aquilo que submete a identidade à temporalização e ao espaçamento, ou seja, é o conteúdo e a forma da revelação do mundo como teatro, deslocalização, como "disfarce" (ou maquiagem). O testemunho dessa lógica, ou sua denúncia, não pode atribuir-se um lugar à parte. A técnica é aquilo que cai na nossa cabeça, quer se queira ou não. Não há o homem sem essa "condição instrumental”*; a humanidade do homem se produz como fato da técnica, tornando possível o “antropomorfismo”, e assim o homem é apanhado na contrariedade de uma singularidade improvável. Segundo Christopher Elson, o humanismo de Deguy é aquele "da estranheza e da monstruosidade reconhecidas como fundamentos do humano"*. A “resistência” não é pacífica, é contrariante e contrariada; é uma "guerra-para-a-paz" [guerre-pour-la-paix], segundo a referência a Heidegger* .

A resistência às lógicas da técnica em Deguy não é objeto de uma oposição em nome do humanismo; o presente da técnica não acontece como tal, analisado, por exemplo, em termos econômicos, científicos ou culturais. Por outro lado, mesmo se a técnica é, de alguma forma, generalizada como elemento do pensamento, da política, da cultura, não se trata mais para o poeta de espectralizar essa generalização, torná-la ambígua ou ambivalente, transformá-la em uma abstração sujeita às ordens da razão: um tal presente não se identifica com a figura da deriva da repetição. Diferentemente de Derrida, por exemplo, que, ao reconhecer o "acontecimento" novo, dramatiza o risco de que este acabe não se oferecendo, Michel Deguy, por assim dizer, ocupa a outra ladeira da mesma montanha contrariante ${ }^{5}$. Algo pode não acontecer, sim, mas o quê? De que se trata? Eu diria que lidamos com um pensamento que prefere se interrogar sobre o fato daquilo que aparece: "O que veio a ser/ É preciso dizer"*; sobre o acontecimento de algo que tem dificuldades em aparecer para a linguagem e para a memória: “O que não pode ser dito.../ Deve ser escrito”* . Essa contrariedade já está na formulação (em português, no original, acompanhado da versão francesa) que põe em jogo a possibilidade do novo, do que acontece:

\footnotetext{
5 “Será que é a 'desconstrução' que desenlaça o dualismo, e seus pares, sem niilismo?” Deguy, Michel. Un homme de peu de foi (Paris: Bayard, 2002: 126).
}

" “Amérique' éveille chacun à sa contradiction" (Deguy, Michel. Choses de la poésie et affaire culturelle. Ob. cit.: 112).

" (Stiegler, Bernard. Latech nique et le temps, I. Paris: Gallilée, 1994).

"(Elson, Christopher. "Anthro pomorphose: I'humanisme dans la poétique de Michel Deguy", Littérature, n. 114 juin 1999: 97).

" (Deguy, Michel. Le spleen de Paris. Ob. cit.: 113).

" "Ce qui a lieu d'être/ Ne va pas sans dire" (Deguy, Michel. Poèmes (1980. 1995). Paris: Gallimard, 1999: 122).

" "Cequ'on ne peutpas dire.../ Il faut l'écrire" (: 122) 
" (Deguy, Michel. Au jugé Paris: Galilée, 2004: 123).

"(Deguy, Michel. Choses de la poésie et affaire culturelle. Ob. cit.: 9).

" "inventer des paradoxes "sublimes" (Deguy, Michel. Au jugé. Ob. cit.: 150).

- "il est déraisonnable de tenir pour raisonnable l'espoir de s'entendre" (Deguy, Michel. Le Spleen de Paris. Ob. cit.: 35 ).

\section{O que sucede nunca sucedeu}

O que sucede já sucedeu

Mas o que sucede?*

Esse trecho está suspenso no coração de "A rosa das línguas", cercado pela narrativa de uma experiência muito viva e perplexa do contemporâneo, e seguido por alguns versos que acentuam sua teologia negativa, típica, aliás, de Fernando Pessoa (a quem o poema é dedicado). Não há algo como o novo: o último verso (“Mas o que sucede?”) é, em primeiro lugar, uma falsa questão (uma “questão retórica”) que indica a impossibilidade do acontecimento, do "divino", a diferença radical do presente em relação a si mesmo: "Nunca um corpo de deus jorrou da pedra”. Mas (e há um “mas” nessa frase) o verso pode ser tomado também por outro lado: "Mas o que sucede?”, que coisa é essa que tem lugar numa temporalidade em que nada pode acontecer sem já ter acontecido, em algum outro lugar. O double bind assim modulado nos deixa diante da necessidade de levar em conta o acontecimento no risco ou no desejo da contrariedade na perspectiva do "interesse geral”. Deguy sublinha o risco ou o desejo de designar este que e também, portanto, seu sujeito, o quem desse que e, enfim, o que do quem, o "Quem o Que” ["Qui Quoi], título de um poema de Tombeau de Du Bellay, no qual o amor é o amor do que não existe, amor indiferente, amor de dar ódio, oximórico. ${ }^{*}$ A meu ver, o desejo desse oxímoro apaixonado, a "tarefa” de "inventar paradoxos 'sublimes"* ocupa cada vez mais o primeiro plano na poesia de Deguy, e sua tonalidade se estabelece pela via de uma certa alegria, e não da angústia ou da ingratidão contrariada ${ }^{6}$.

Em Spleen de Paris, afirma-se uma "ligeira preferência" por um dos modos de pensar o paradoxo: à formulação "é razoável considerar como não razoável a esperança de entender-se”, Deguy prefere uma outra: “não é razoável considerar como razoável a esperança de entender-se”* . Trata-se, portanto, de uma preferência, de uma afeição na qual se faz a escolha da contrariedade em oposição à esperança do razão razoável. Essa contrariedade que parece querer afirmar calorosamente algo como "que loucura acreditar

\footnotetext{
${ }^{6}$ Propus a análise da contrariedade ingrata em Jacques Derrida no tex to "A paixão ingrata”. Em: Nascimento, Evando e Glenadel, Paula. Em torno de Jacques Derrida (Rio de Janeiro: 7 Letras, 2000).
} 
nisso!" enfatiza a necessidade da tonalidade afetiva da proximidade ou da aproximação. Deguy parece buscar, portanto, uma contrariedade não sacrifical, uma crítica ao humanismo sem a experiência de se abandonar-se como homem, sem aceitar o fato do niilismo; ele denuncia o antropomorfismo, sim, mas se atribui a tarefa da experiência da prosopopéia, o processo de um devir-humano que ele chama "antropomorfose". "Repatriemos no homem os oxímoros divinos que a ele pertencem: a responsabilidade poética é a de superhumanizar o homem"*.

E o que seria uma contrariedade não sacrifical?

Bataille conta que, ainda muito jovem, "caótico e cheio de ebriedade vazia”, ele percorria a rua de Rennes deserta, tarde da noite; mantinha o guarda-chuva aberto, ainda que não chovesse. Repentinamente, o guarda-chuva se fechou sobre sua cabeça e no "rapto" devido ao acaso, ele se cobriu "intencionalmente com este sudário negro" e sorriu "divinamente", "como se estivesse morto"*. O suplício do passante parisiense remete à angústia e seu riso se aproxima perigosamente do nonsense da loucura de um eu transformado em outro. $\mathrm{O}$ riso louco de um outro homem é o que anula o risivel do homem. "Este homem deveria matar este que sou, tornar-se a tal ponto ele mesmo que minha estupidez cessaria de fazer-me risível"*. Cito essa passagem para introduzir uma idéia um pouco diferente, a da resistência preciosa, talvez "ridícula". Eis algo bastante singular: Deguy não ri do mesmo modo que Bataille e seu prazer não está na anulação do sentido ${ }^{7}$ ou no apagamento do risível. Na poesia de Deguy, o "desespero" procura definir-se por sua "energia" e essa emoção, no "calor" afiado, contrariante, resiste à "abstinência do sentido", à redução da "coisa a seu não-senão"* intolerável.

\section{Um pensamento "ecológico”}

Em Le spleen de Paris, título que homenageia Baudelaire, a questão da técnica torna-se uma questão mais heideggeriana do que baudelairiana, ou seja, tanto uma questão de "serenidade" quanto de "choque" (W. Benjamin). A cidade de Paris é apresentada por alguém que faz questão de afirmar e de repetir

${ }^{7}$ Em La raison poétique (2000), Deguy fala sobre o equívoco do "nonsense" como modalidade "covarde" do dizer. Uma alusão a esse problema se encontra no texto "Defesa e ilustração da poesia” (Em: Deguy, Michel. A rosa das línguas. Ob. cit.).
"Repatrions en l'homme les oxymores divins qui lui reviennent: la responsabi. lité poétique est de le sur. humaniser" (Deguy, Michel. L'Énergie du désespoir. Ob. cit.: 32)

" (Bataille, Georges. L'expérience intérieure. Paris: Gallimard, 1954: 47).

" (Ibid.: 46) * "l'abstinence du sens",
"la chose à son ne-que"
(Deguy, Michel. L'Énergie
du désespoir. Ob. cit.: 7). 
"À quoi pense-t.elle (la poésie)? J'ai pensé à Bau. delaire, à Paris, à la terre". (Deguy, Michel. Le spleen de Paris. Ob. cit.: 55).

que ama Paris, que gosta de chegar em Paris, viver em Paris. Que viaja para poder amar Paris. Paris é o lugar da poesia, da singularidade, do corpo. O texto termina com a designação de seus objetos: "Em que ela pensa (a poesia)? Pensei em Baudelaire, em Paris, na terra"*, no entanto a grande cidade é mostrada, antes de tudo, a partir de seu aspecto menos favorável, geralmente vista pela ótica cultural da prioridade dada ao turismo ou ainda da propagação do "servilismo" à cultura americana. Paris é figura do que deixa ver, sobretudo por seus problemas de trânsito, nada menos do que a questão da sobrevivência. O spleen característico de Deguy, meditativo, porém duro (dureza que tem a preocupação, em $O$ spleen de Paris, de não ser vista como um mau humor típico da idade), não reproduz a retórica de ficção dos poemas em prosa de Baudelaire; ele prefere a aproximação calorosa e apostrofante dentro do gênero retórico de uma pensividade crítica.

Detenho-me neste texto porque encontro nele um figurante geral dessa relação com a técnica que sugere, ao mesmo tempo, questões geopolíticas (aqui chamadas “ecológicas”) e a contrariedade da relação com o contemporâneo. Trata-se das regras de circulação e das relações entre automóveis, pedestres, veículos em geral. Sabemos que o automóvel é um elemento freqüentemente associado à técnica e, de resto, a seus problemas colaterais, como a poluição. Ora, Paris, como toda grande cidade, ao mesmo tempo que tem a cultura, as condições práticas e uma legislação que estimula a caminhada, também possui seus automóveis, seus ônibus, seus caminhões, suas motos. Os automóveis têm suas leis, suas "prioridades"; produtos fetiches da razão tecnológica, eles também possuem, em geral, o privilégio de uma lei que excede a consideração do humano e da vida:

Altercação. Chego na avenida de bicicleta, vindo de uma ruela. $\mathrm{O}$ automóvel tem a prioridade; ele me acidenta, porque ele "tem razão".

- "Você tem razão! Isso não é uma razão!"

Portanto, não é a razão da Razão que decide em última instância sobre o que é bom. Ela se inclina e se coloca na dependência de um outro dispositivo do julgamento. Qual?
Altercation. Je débouche à vélo, d'une ruelle dans le boulevard. La voiture a priorité; elle m'accidente, parce qu'elle "a raison".

- “Tu as raison! Ce n'est pas une raison!"

Donc ce n'est pas la raison de la Raison qui décide en dernier lieu de ce qui est bon. Elle s'incline et s'en remet à un autre ressort du jugement. Lequel?* 
Em última instância, a razão da circulação (criada para regular as relações e, portanto, diminuir o risco de acidentes) justifica, ao contrário, a violência dessas relações, torna-a racional, razoável. Ao excluir a injunção do outro, da qual se originou, a lei se torna um fim nela mesma.

O pedestre em geral é o excluído das regras de trânsito, que privilegiam os veículos motorizados. O pedestre está do lado da caminhada, das pernas, do pé sobre a terra. O pedestre se torna facilmente um homem que flana, sem objetivo, sem direção. Não em Paris, onde o pedestre passa a assegurar a continuidade da caminhada, tomado "pelo império do objetivo, ébrio de seu projeto"*. Como corpo não razoável, o pedestre "urbantropo" é "egocentrado", e até "autístico"; caminha como se a calçada fosse toda sua, bem como a rua e o mundo inteiro: ele "ignora seu outro". Se existem regras que lhe dão "prioridade absoluta", trata-se muito mais de uma ilusão que facilita o acidente. $\mathrm{O}$ homem tomado pela exceção de sua condição de pedestre se embriaga de sua fragilidade e se crê salvaguardado pela regra: "Este absoluto o acidenta"*.

O hedonismo do pedestre (não exatamente irresponsável, mas falsamente protegido) não é, pois, uma alternativa ao "niilismo" da circulação de automóveis. Mas o que seria então? O spleen de Paris orienta nosso olhar ao ciclista. Mais recentemente, em Au jugé, Deguy intitula uma de suas "crônicas": "Da bicicleta em geral e do ciclista parisiense em particular". Ele defende a prática da bicicleta, tal como se observa em Paris, ainda que raramente, "com virtude e virtuosidade", e não necessariamente nos limites da lei, que é falha justamente neste caso. Tal "filosofia da circulação urbana", empreendida por meio da retórica de uma carta aberta, dirige-se aos policiais de Paris a fim de interferir na tensão que só aumenta entre a lei e a bicicleta. Em $O$ spleen de Paris, o ciclista aparece mais singularizado, "o nariz sobre o guidão, o olhar bem à frente para aparar o inopinado"*. O ciclismo disputa seu lugar com o "cinismo", seja das regras meio-completas (como das pistas que se interrompem), seja dos paradoxos da relação com o excremento nas calçadas: "[...] as senhoras KK [em francês, a sigla lê-se sonoramente como "cocô" $]$ vivem no cu de seus cães [" $\operatorname{dog}($ ue)s", que joga com a forma inglesa da palavra] [...] nunca respeitam a lei”*.

O estatuto da bicicleta, portanto, é ambíguo: mesmo que esteja mais próxima do pedestre, como veículo movido por mús-

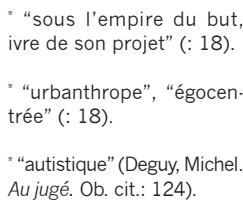

" "autistique" (Deguy, Michel. Au jugé. Ob. cit.: 124).

" "Cet absolu l'accidente" (: 124).
* "Du vélo en général et du cycliste parisien en particulier"; "avec vertu et virtuosité" (: 125).

" "philosophie de la circula tion urbaine" (: 125).

\footnotetext{
" "le nez sur son guidon, le regard à cent pas pour parer à l'inopiné" (Deguy, Michel. Le spleen de Paris. Ob. cit.: 17)

" "[...] mesdames KK vivent au cul de leurs dog(ue)s [...] elles n'observent ja. mais la loi" (Deguy, Michel. Le Spleen de Paris. Ob. cit.: 18).
} 
"(Deguy, Michel. Le Spleen de Paris. Ob. cit.: 15).

culos, não pode ocupar o espaço que pertence ao caminhante; de fato, existem pistas especiais para a bicicleta. Porém...

A pista é inútil, até mesmo perigosa: ela se interrompe, não conduz a lugar algum, desemboca em um trânsito no qual não significa mais nada: prescritiva por vezes, ao que parece, ela desperta, no momento em que sua pintura desaparece da calçada, a cólera do carro que ameaça o ciclista desatento em relação à “sua pista”.
La piste est inutile, voire dangereuse: elle s'interrompt, elle ne conduit nulle part, débouchant dans un trafic où le vélo n'est plus rien: prescriptive par endroits, semble-t-il, elle inspire alors, au moment où sa peinture disparaît de la chaussée, la colère de l'auto qui menace le cycliste oublieux de "sa piste".

A relação do ciclismo com a lei de trânsito é, portanto, tensa em sua imprecisão ou, antes, em seu double bind (siga-me, não me siga); no fundo, em sua ambivalência, o espaço da bicicleta indica o lugar excluído da reflexão sobre a circulação, isto é, aquele da descontinuidade entre a lei técnica e o interesse do homem, este que supostamente teria como objetivo assegurar.

Ora, pensar a singularidade em sua condição de exceção não muda muita coisa. É razoável pensar na incompatibilidade entre a bicicleta e o automóvel, mas é “preferível” para Deguy dramatizar o caráter não razoável da crença de que a bicicleta e o automóvel (cujo número é sempre crescente) possam juntos encontrar a paz. É esse princípio que leva à necessidade de uma razão “ecológica”, já presente na relação com a identidade humana, e mesmo com a tecnologia humanista.

\section{O homem ridículo}

A cena do ciclista que vai parar na avenida e se acidenta faz lembrar um trecho conhecido de $O$ spleen de Paris, de Baudelaire. Neste fragmento, o poeta decaído, diante da surpresa de um amigo que o encontra em um lugar suspeito [mauvais lieu], responde:

- Meu caro, você conhece o terror que tenho de cavalos e veículos. Há pouco, ao atravessar o bulevar, apressado, no momento em que saltitava no barro, no meio desse caos movente no qual a morte vem a galope de todos os lados ao mesmo tempo, minha auréola, num movimento brusco, escorregou da minha cabeça e caiu na lama. Não tive coragem de pegá-la. Achei que seria menos desagradável perder minhas insígnias do que ter meus ossos quebrados. Além disso, disse a mim mesmo, em tudo há 
um lado bom. Agora, posso circular incógnito, realizar ações desprezíveis e tornar-me canalha, como os simples mortais. Eisme aqui, parecido com você, como pode ver!*

O poeta decaído é, portanto, simples mortal. Nisto, é semelhante ao amigo, não por amizade, mas por sarcasmo, e semelhante aos outros (como vemos na seqüência do texto) pelo prazer divertido de pensar no ridículo dos maus poetas que quererão recuperar o objeto perdido. "Simples mortal” é, pois, aquele que coloca a semelhança com o homem no campo problemático da hipocrisia. Essa situação é retomada de modo significativo por Deguy no trecho "Meu semelhante meu irmão”, referência direta a Baudelaire, em O spleen de Paris: me sirvo com prazer para pintar je me sers volontiers pour pein"o homem” quando, destacado, dre "l’homme" quand, détaché, "divino” (de bicicleta, por exemplo), olho vivaz invisível entre eles, eu os percebo. Sinto que somos ridículos, mas em que, por que, como? “divin” (à vélo, par exemple), oeil vivant invisible parmi eux, je les remarque. Je sens bien que nous sommes ridicules, mais en quoi, pourquoi, comment?*
"Ridículo" é o predicado de que "Ridicule" est le prédicat dont

"(Baudelaire, Charles. Oeuvres complètes, I. Paris: Gallimard, 1975: 352).

"(Deguy, Michel. Le spleen de Paris. Ob. cit.: 48).

O homem de bicicleta é "divino", singular; seu olho vivaz - que o poeta advinha no meio da multidão - o destaca da coletividade que repentinamente tem lugar, é percebida. Fazendo-se perceber como único, sendo "tal que a si mesmo" apenas entre outros, destacando-se, portanto, ao fazê-los notar, o ciclista denuncia a "encenação geral", , na qual cada um gostaria de parecer consigo mesmo por meio da anulação do outro. O homem de bicicleta é, assim, o figurante dessa aventura da singularidade que Deguy encontra na "freqüentação das cidades enormes". O homem sobre sua máquina não carrega as insígnias legais do caminhante ou do motorista. Está simplesmente no lugar errado, em um "mauvais lieu”, marginal, excluído do ponto de vista da circulação, o que, à diferença de todos os outros, torna-o como todos os outros, isto é, ridículo ${ }^{8}$.

${ }^{8}$ Diferentemente do uso da palavra em À ce qui n'en finit pas (Deguy, Michel. À ce qui n'en finit pas. Thrène. Paris: Seuil, 1995), no qual "ridículo" parece opor-se a "magnífico" como atributo do homem em seus diferentes estados, aqui ele parece resumir justamente uma condição contrariante.
" "mise en scène générale" (Deguy, Michel. L'Énergie du désespoir. Ob. cit.: 31). 
" (Deguy, Michel. Le spleen de Paris. Ob. cit.: 48).

"(: 48).

" "Il faut se pardonner mutuellement le ne-que" (: 49).

" (Baudelaire, Charles. Oeuvres complètes, I. Ob. cit.: 320).

No fragmento em questão, Deguy discute as condições do ser-semelhante. Em suma, o homem é ridículo por não ser senão ele mesmo, por não ser ele mesmo senão graças a um aspecto particular, isto é, por não ser senão um “tipo homem”, segundo uma estrutura do não-senão [ne-que]. As crianças, por exemplo, irritam-se quando uma se faz de papagaio repetindo o que a outra disse: as crianças não perdoam a confusão entre o traço distintivo e o traço típico:

Se a definição de homem é ser um semelhante, "meu semelhante", ser ao ser semelhante, então trata-se da mesma coisa que é ao mesmo tempo a essência e o ridículo. Como resolver isso?
Si c'est la définition de l'homme d'être un semblable, "mon semblable", d'être en étant semblable, c'est donc une même chose qui est à la fois l'essence et le ridicule. Comment s'en sortir?*

Segundo Deguy, "é preciso perdoar-se mutuamente o não-senão"*, pois a semelhança não pode ser concebida sem a abdicação de todo predicado, sem que se possa "tolerar o não-senão inimitável ridículo do outro"*. É somente constatando e perdoando o ridículo do outro que eu posso ser parecido com ele.

O homem semelhante enquanto homem ridículo não supõe o sacrifício preliminar de sua diferença risível. A questão é mais complicada em Baudelaire, que concebe a superioridade da vítima no contexto de uma crítica à proteção paradisíaca, paraíso baseado no privilégio de ser exclusivamente o carrasco do outro. O "interesse geral" manifesta-se em Baudelaire como um "interesse capital" ${ }^{9}$. Em Deguy, o homem quer viver em comunidade pelo ridículo, por uma certa solidão sem isolamento, por uma desapropriação sem esterilidade, por uma singularidade sem coincidência consigo mesmo, por um "como-um" [comme-un].

Deguy oximoriza o paradoxo que há no ser-semelhante (a identidade e o intolerável) do homem; denuncia o teor pas-

\footnotetext{
${ }^{9} \mathrm{~A}$ análise dos fragmentos de Baudelaire sobre a pena de morte (Journaux intimes) é significativa para a compreensão de suas posições políticas e poéticas em torno da figura do "herói" ou do "mártir". Foucault fala de uma "heroisação irônica do presente" (citado por Deguy, Michel. La raison poétique. Ob. cit: 25). É assim que, em um dos poemas em prosa de Baudelaire ("Une mort herö̈que"), o narrador expõe as intenções de um Príncipe de colocar à prova o artista que havia traído sua confiança. $\mathrm{O}$ ator, representando para seu Príncipe com o risco da própria vida, "ia, vinha, ria, chorava, convulsivamente, com uma indestrutível auréola em torno da cabeça, auréola invisível para todo, mas visível para mim, onde se misturavam, em estranho amálgama, os brilhos da Arte e a glória do Mártir" (Baudelaire, Charles. Oeuvres complètes, I. Ob. cit.: 321 ).
} 
sional relacionado a esse oxímoro, teor que mata e faz matar; dramatiza o ridículo daquilo que sucede pela encenação de um passante de bicicleta, que interpela o sentido da lei, que negocia incessantemente seu espaço como espaço comum, que não hesita, portanto, em encenar certa "preciosidade" na relação com o trânsito e a circulação da cidade grande. $\mathrm{O}$ mesmo pode ser dito sobre seu estilo "difícil", muito rápido, muito impregnado de filosofia, contrariante, nem sempre em relação de pertinência com o que se gostaria de crer que fosse "a humana pista" (Tristan Corbière). É preciso perdoá-lo.

As figuras de circulação urbana imprimem uma marca bastante singular em $O$ spleen de Paris. Não se trata de generalizar a bicicleta como solução técnica dos problemas de circulação ou de tê-la como modelo de uma aventura que se opõe à lei geral. Trata-se antes de compreendê-la como figurante de um ridículo que não se confunde com a exceção ou com a "minoria”, e que é preciso aceitar para não se deixar conduzir pela homogeneidade destruidora contida na expansão mundial da técnica. Nesse sentido, uma concepção "revolucionária" do espaço urbano não está exatamente no respeito à exceção, mas em um pensamento ecológico, cujo "programa está longe de ser compreendido, e mais ainda de ser aceito"*. O pensamento ecológico, pode-se perceber, não exclui uma razão poética; ao contrário, ele a supõe.

\section{Marcos Siscar}

Professor da Unesp (São José do Rio Preto), tradutor e pesquisador do CNPq. Publicou Jacques Derrida. Rhétorique et philosophie (L'Harmattan, 1998) e organizou, com Cristina Rodrigues, o volume Tradução, desconstrução e pós-modernidade (Alfa, n. 44, 2000). Como tradutor, publicou obras de Tristan Corbière (Iluminuras, 1996), Michel Deguy e Jacques Roubaud (Cosac \& Naify, 2004 e 2006), com Paula Glenadel.
" "programme n'est pas près d'être compris, enco re moins accepté" (Deguy, Michel. Le spleen de Paris. Ob. cit.: 29) 
Key words

French poetry

Michel Deguy

technique

humanism

Mots-clé

poésie française

Michel Deguy

technique

humanisme.
Recebido em 30/03/2006

Aprovado em 10/04/2006

\section{Resumo}

O trabalho analisa a obra do poeta e teórico Michel Deguy, do ponto de vista de sua leitura dos problemas da técnica no contemporâneo. Ao retomar o percurso da questão na obra do autor, vemos que o tema da natureza se retrai paulatinamente, dando espaço a um questionamento sobre as diversas figuras do "progresso" técnico e levantando problemas geopolíticos, culturais e poéticos. Apesar de aparecem ao longo de quase toda sua obra, essas figuras estão singularmente apresentadas no livro $O$ spleen de Paris (2001), título que expõe significativamente a raiz baudelariana do assunto. Nesse livro, as observações sobre o problema do tráfego urbano (carros, pedestres, ciclistas) ganham dimensão político-poética e sua retórica ajuda a entender o modo pelo qual o autor apresenta o sentido "humanista" da poesia.

\begin{abstract}
This paper investigates the work of poet and theorist Michel Deguy from the point of view of his understanding of the question of technique in the contemporary world. Retracing Deguy's steps, it notes that nature as a topic gradually recedes into the background, thus opening the way to the scrutiny of divers figures of technical "progress", which then lead to the emergence of geopolitical, cultural and poetical issues. Even though they appear virtually throughout his work, these figures are to be found most forcefully in Le spleen de Paris (2001), a title that significantly points to the roots of the subject in Baudelaire. There, urban traffic (cars, pedestrians, bikers) acquire a political-poetical dimension and its rhetoric helps one grasp the fashion in which the author conceives of the "humanist" sense of poetry.
\end{abstract}

\section{Résumé}

Ce travail propose une lecture de l'oeuvre du poète et penseur Michel Deguy du point de vue de sa perception des problèmes de la technique. L'analyse du parcours de cette question nous montre que le thème de la nature se retracte dans ses textes à la mésure où le poète ouvre la voie d'une mise en question des différentes figures du "progrès" technologique, en soulignant des complicités géopolitiques, culturelles et poétiques. Même si elles se font remarquer tout au long de la trajectoire poétique et théorique de Deguy, ces figures sont singulièrement présentées dans le volume Le spleen de Paris (2001), titre qui expose la racine baudelairienne du sujet. Dans ce texte, les ponctuations sur le problème de la circulation urbaine (voitures, piétons, cyclistes) gagnent une dimension politico-poétique, et leur rhétorique aide à comprendre la façon par laquelle l'auteur présente l'enjeu "humaniste" de la poésie. 